\title{
Championing rural medicine
}

\author{
Interview with Dr Ken Milne
}

Sissi Cao (Meds 2016), Han Yan (Meds 2017)
Faculty Reviewer: Dr Ken Milne, MD, MSc, CCFP(EM), FCFP (Department of Emergency Medicine)

Dr Ken Milne is an emergency department physician, Chief of Emergency and Chief of Staff at South Huron Hospital Association in Exeter, Ontario. He has been an advocate for advancing the practice of rural medicine throughout his career. Originally from a farm just outside of London, Dr Milne completed both his undergraduate and graduate degrees at Western University before attending medical school in Calgary. He returned to Western in 1997 for family medicine training and began his medical career in Goderich, where he currently resides with his wife and 3 children. In addition to being a clinician, Dr Milne has been conducting research on rural medicine for the last 17 years and helped establish what is now Discovery Week, an integral part of the Schulich School of Medicine's first-year curriculum. He is also the creator of the knowledge translation project “The Skeptic's Guide to Emergency Medicine” (SGEM), which disseminates evidence-based information online so patients can receive the best care. We met with Dr Milne over Google Hangouts to talk about his colourful career, the unique aspects of rural medicine and the challenges he faces working in a remote location.

\section{UWOMJ: What was your path to choosing rural medicine?}

Ken Milne: In 1997, when I graduated and came back for my residency, the OMA came out with the Geographic Redistribution Program to drive physicians out of urban centers. If you stayed in a city where there was a medical school, you would only be paid $70 \%$ of your billings. But if you moved away, you could get $100 \%$. My wife and I drew a circle around London, where all our family was, and an opportunity came up in Goderich where we live now.

\section{Describe to us the community you currently serve and what makes it unique.}

The community I serve now is Exeter in South Huron. It has about 4000 residents and it's mainly a farming community. It also services the tourist community of Grand Bend. The unique aspect of practicing in a rural area is that I get to be the "ologist": I get to be the cardiologist, the gastroenterologist, the orthpediologist, the pediatrologist and the gynecologist. We don't have any operating rooms or regular access to a surgeon. General surgery, pediatrics, gynecology, dermatology and internal medicine rotate through weekly, biweekly or monthly during visiting clinics. So in between the one time a month when a pediatrician comes, I am taking care of all the children. We are able to take care of most of the cases without referring to someone in an urban center.

\section{What do you enjoy most about rural medicine?}

I get to use all my skills, knowledge and abilities to their fullest. In an urban environment, you have to have more of a niche practice because of all those other specialists and sub-specialists around you. As a rule in rural areas, we are it. And I love that.

\section{Tell us about your research. Is there anything specific you focus on?}

My research for the last 17 years has been on rural medicine. It involves focusing on issues in rural medicine and the delivery of rural care. It's a golden age for rural research. There are so many untapped questions out there that haven't been answered. They have been answered in urban environments but they haven't been answered in rural environments and there's a big difference between urban and rural delivery of care. The more research I do, the more I understand the kind of care we give.

\section{You were mentioning the differences between rural and urban delivery of medicine. Can you go into some of those differences?}

In rural medicine, we are very much "high thought, low tech." I don't have access to an x-ray lab after a certain time of night. Unless I ship my patient out, I don't get that CT scan, or MRI, or consult. We really have to use my brain: we are inventive, we are early adaptors, we are creative out of necessity. We don't have access to the advanced imaging or to specialists. A patient would have to travel a great distance to get to them. If we can figure out something that would normally be referred out, we can take care of them locally.

\section{We wanted to highlight the fact that you don't have to be at a tertiary care center or have a master of clinical epidemiology in order to conduct good research.}

Yes, you don't need to. I have support through the Southwestern Ontario Education Network (SWOMEN) and Gateway Rural Health Research Institute, the only rural research institute in Canada, where I am currently the Chair of Rural Medicine. These are institutions that make a huge difference by supporting rural teaching and research. And I like that SWOMEN sends me students who challenge me and keep me on my toes.

\section{What are the most challenging aspects of rural medicine?}

Professionally, the biggest challenge is obtaining access to advanced imaging and to specialists when I need them. The farther you are from a patient, the more dismissive a physician tends to be. I 


\section{PROFILES}

need to make sure that rural patients get the care that they deserve, no matter where they are. On a personal level, living in a small town can be a challenge for a spouse, for children and in terms of opportunities you may or may not want them to have, be it parks, or sports, or academics. That might be hard for certain people. Rural communities tend to be lovely, but homogenous. .

\section{How do you address these challenges?}

Advocate for your patients. Never give up. That's the only thing. It starts with patient care and ends with patient care. The stuff in the middle doesn't matter. They get the care they need and deserve. And do it in polite and professional way.

\section{How do you think rural medicine or research will change in the future?}

Research may become more difficult due to centralization-everyone seems to be choosing the care closest to home. We are rural academic centers of excellence with amazing programs and success stories from the periphery that Schulich can learn from. It's a twoway street.

In going rural, one of the most amazing things I've seen happen is information technology. It has shrunk the world and made access to information easier than ever before. We need to start teaching medical informatics instead of the procedures themselves. You can't possibly cram every procedure and every clinical scenario into your head, but you can learn an approach and how to access the knowledge you need.

\section{Tell us about your involvement with what is now Discovery Week. What was the drive to start a rural week?}

James Rourke, now the dean of Memorial University, and I set up Rural Week in 1997. He knew I was interested in research and teaching and he made me its undergraduate coordinator for the first three years. He founded Southwestern Ontario Rural Medicine (SWORM), before it became SWOMEN. He wanted to give every single first-year student exposure to rural medicine, even if he or she may never want to do rural medicine. We conducted research and Rural Week was the most highly rated mandatory course of first year, for educational value, and it gave people great first experiences.

\section{Is there a certain personality that fits with rural medicine? Is there anything else you wish you had known as a medical student?}

The personalities that go rural are the early adapters who can really use all their skills and knowledge and resources.

What I would tell anybody is just figure out what gets you out of bed in the bed, what keeps you working hard all day and what makes you stay late. That's what you should do the rest of your life. If it happens to be rural, great; if it's not, great too.

\section{Any last take-home words about rural medicine?}

Rural medicine generally allows people to have full practice patterns and the opportunity to exercise their abilities, knowledge and skills to the fullest. You have the privilege of an intimate rela- tionship with your patients, you are able to make a difference at a one-on-one level and also see patients around town. I'm not only part of that patient's life, but I am part of the community life. I get to make a difference on an individual basis, on a community basis, and because of research, I get to advance medicine for all rural communities.

Dr Milne has recently been awarded the Teacher of the Year Award for Canada by the Canadian Association of Emergency Physicians for his work on SGEM and the Schulich Award for Excellence for Faculty in Distributive Sites for his outstanding contributions to medical education. His passion for patient advocacy, innovative nature and ability to put his ideas into motion makes him the perfect champion for rural medicine and medical education. 